\title{
Enantioselective Baeyer-Villiger Oxidation
}

Desymmetrization of meso-cyclic ketones:<smiles>[R]C1CCC(=[O+])CC1</smiles><smiles>[R]C1CCOC(=O)CC1</smiles><smiles>[R]C1CC(=O)C1</smiles>

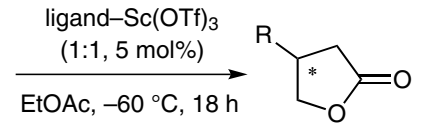

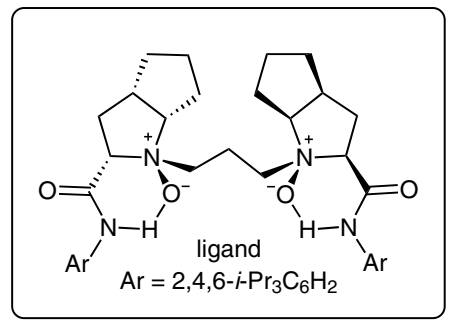

Kinetic resolution of racemic cyclohexanones:

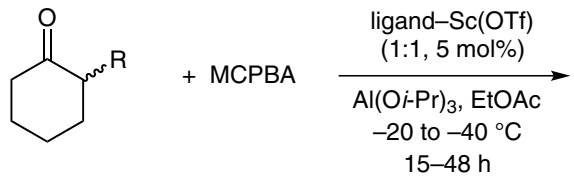

Selected examples of desymmetrization:
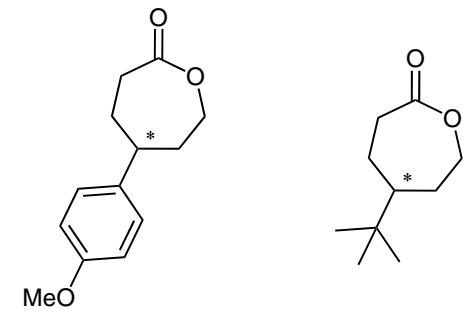

$81 \%$ yield, $95 \%$ ee<smiles>O=C1CCCCC1</smiles><smiles>[CH2+]CC</smiles>

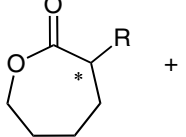

AL
Gategory

Metal-Catalyzed Asymmetric Synthesis and Stereoselective Reactions

\section{Key words}

Baeyer-Villiger oxidation

scandium

desymmetrization

Selected examples of kinetic resolution:

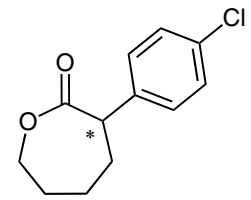

$\mathrm{AL} / \mathrm{NL}>19: 1$ $93 \%$ ee $(A L)$

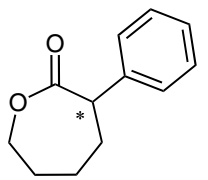

$\mathrm{AL} / \mathrm{NL}=16.5: 1$ $90 \%$ ee $(A L)$<smiles>Cc1cccc(C2COC(=O)C2)c1</smiles>

$80 \%$ yield, $91 \%$ ee<smiles>O=C1CC(Cc2ccc3c(c2)OCO3)CO1</smiles>

$99 \%$ yield, $80 \%$ ee

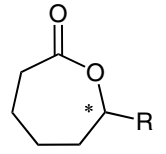

NL

(abnormal lactone) (normal lactone)
Significance: The asymmetric Baeyer-Villiger oxidation of prochiral and racemic cyclic ketones effectively synthesized optically active $\varepsilon$ - and $\gamma$ lactones. The desymmetrization of racemic cyclohexanones interestingly showed a reversal of migratory aptitude with high levels of enantioselectivity.
Comment: The authors continued their use of chiral N,N'-dioxide-metal catalysts for the BaeyerVilliger oxidation reaction. During the desymmetrization of meso-cyclohexanones and meso-cyclobutanones, the electronic and steric nature of the substituents appeared to have no effect on enantioselectivity; the opposite was true for the kinetic resolution of racemic cyclohexanones.

SYNFACTS Contributors: Hisashi Yamamoto, Kimberly Griffin

Dol: 10.1055/s-0032-1317774; Reg-No.: H15412SF 